\section{RAPID SEQUENCE INTUBATION IN SCOTTISH EMERGENCY DEPARTMENTS}

Airway management, in particular rapid sequence intubation (RSI), is a core skill in emergency medicine. The RSI debate continues between UK emergency physicians and anaesthetists. This large prospective, multicentre Scottish urban study aimed to examine emergency intubation practice, whether performed by emergency physicians or anaesthetists. Anaesthetists obtained better views at laryngoscopy and achieved higher initial success rates, but emergency physicians intubated a higher proportion of unstable patients and a higher proportion within 15 minutes of admission. Complications were fewer in the anaesthetists' group, but this may be related to differences in patient populations. See page 3

\section{CHILD SEIZURE GUIDELINE}

Seizure is a very common presenting complaint of children attending an accident and emergency department. Once the seizure is under control there are wide variations across the country in investigations and management, including admission decisions. This paper describes a systematic literature review to find the best evidence for correct management from presentation to discharge. The literature evidence was poor, however, and was insufficient to base clinical decisions on. Where this literature was lacking a formal Delphi Consensus Development process was undertaken to produce a practical clinical guideline in algorithm form, which is presented here.

See page 13

\section{POST-TRAUMATIC STRESS AMONG AMBULANCE PERSONNEL}

Ambulance personnel are often exposed to traumatic events when helping people in emergency situations and ambulance workers have been shown to be vulnerable to the development of a symptom of post-traumatic stress. Current literature mainly focus on post-traumatic stress after disasters and very few have investigated the daily work as cause of stress reactions. This paper explores the prevalence of post-traumatic stress reactions among Swedish ambulance personnel in daily work. The result shows that over $15 \%$ had indication of stress reaction with certain likelihood of post-traumatic disorder. The study indicates that lower sense of coherence and longer work experience predicts post-traumatic stress. The high prevalence of post-traumatic stress disorder symptoms in ambulance personnel indicates an inability to cope with stress in daily work. The strong relation between post-traumatic stress and Sense of Coherence Scale may be useful in predicting vulnerability for post-traumatic symptoms among recently employed ambulance service personnel.

See page 79

\section{ARE PEOPLE IN AUSTRALIA INFORMED ABOUT AND PREPARED TO INTERVENE IN A CARDIAC EMERGENCY?}

As few as $22 \%$ of out of hospital cardiac arrests in Melbourne receive CPR from a bystander before the arrival of the emergency medical service. In a phone survey of the Victorian public only $11 \%$ of participants had recently trained in CPR. When presented with a cardiac arrest scenario most participants stated that they would telephone 000, however the number of participants that stated that they would give mouth to mouth or chest compressions, or both, was disappointing.

See page 85

\section{EDUCATION OF ADULTS IS NEEDED IN THE BENEFITS OF DOMESTIC PARACETAMOL FOR FEVERISH CHILDREN}

The antipyretic properties of paracetamol are well documented. Studies identified a lack of knowledge among carers in its benefits for children. This study aimed to determine prehospital paracetamol use by carers presenting with unwell children to the A\&E department. It also reports on the administration of antipyretics by A\&E department staff. Almost one third of feverish children had not received prehospital paracetamol. Knowledge of the properties of paracetamol were associated with administration. Some feverish children did not receive antipyretics in the A\&E department. There is scope for education of carers and A\&E department staff in the administration of paracetamol and other antipyretics.

See page 88 